\title{
Effects of COVID-19 Pandemic on the Mental Health of Pregnant Women
}

\section{COVID-19 Pandemisinin Gebe Ruh Sağlığı Üzerine Etkileri}

\author{
Esma Akpınar Aslan', ๑ Oğuzhan Kılınçel² \\ 'Department of Psychiatry, School of Medicine, Tokat Gaziosmanpasa University, Tokat, Turkey \\ 2Department of Child Development, İstanbul Gelisim University, İstanbul, Turkey
}

\begin{abstract}
Objective: The negative consequences of coronavirus disease 2019 (COVID-19) pandemic on the mental health of pregnant women and the mental disorders it may trigger pose risks for the physical, cognitive and psychological development of infants as well as having risks in terms of the general health and functionality of the mother. This study aimed to investigate the effects of COVID-19 pandemic on the mental health of pregnant women and to evaluate the prevalence of psychiatric symptoms.

Material and Method: The study included a total of 112 pregnant women who agreed to fill an online survey which was provided to them via e-mail. Online survey consisted of sociodemographic data form, questions related to COVID-19, Depression Anxiety Stress Scale-Short Form (DASS-21), and Posttraumatic Stress Disorder (PTSD) Checklist for Diagnostic and Statistical Manual of Mental Disorders-Fifth Edition (DSM-5) (PCL-5).

Results: The mean age of the participants was 31.06 years. The DASS-21 subscale score for depression was $4.20( \pm 3.91)$ whereas it was $3.75( \pm 3.50)$ for the anxiety subscale and $5.68( \pm 3.81)$ for the stress subscale. Total PCL-5 score was $31.29( \pm 16.85)$. Those diagnosed with COVID-19 during the pandemic were observed to show a higher rate of anxiety symptoms. Those who believed that they needed professional support for mental health during the pandemic showed higher rates of depression, anxiety, and stress symptoms. The prevalence of PTSD symptoms were found to be higher among participants who were not health care professionals and who thought they needed professional support for mental health during the pandemic.
\end{abstract}

Conclusion: Determining the effects of the COVID-19 pandemic on the mental health of pregnant women will be important to put early intervention methods in action and implement evidencebased practices.

Keywords: Pregnant, COVID-19, mental health
Öz

Amaç: COVID-19 pandemisinin gebe ruh sağlığı üzerinde yaratabileceği olumsuz sonuçlarve tetikleyebileceği ruhsal bozukluklar, annenin genel sağlığı ve işlevselliği açısından riskler barındırmasının yanında bebeklerin fiziksel, bilişsel ve psikolojik gelişimleri açısından da risk oluşturmaktadır. Bu çalışmada COVID-19 pandemisinin gebe ruh sağlığı üzerine etkilerini araştırmak ve psikiyatrik semptomların yaygınlığını değerlendirmek amaçlanmıştır.

Gereç ve Yöntem: Çalışmaya kendilerine e-mail yolu ile iletilen online anketi doldurmayı kabul eden 112 gebe dahil edildi. Online anket; sosyodemografik veri formu, COVID-19 ile ilgili sorular, Depresyon Anksiyete Stres Ölçeği-Kısa Form (DASS-21) ve DSM-5 için Travma Sonrası Stres Bozukluğu Kontrol Listesi 'nden (PCL-5) oluşmaktaydı.

Bulgular: Katılımcıların yaş ortalaması 31,06 idi. DASS-21 depresyon alt ölçek puanı $4.20( \pm 3,91)$, anksiyete alt ölçek puanı 3,75 $( \pm 3,50)$, ve stres alt ölçek puanı 5,68 $( \pm 3,81)$, PCL-5 toplam puanı ise 31,29 $( \pm 16,85)$ olarak saptandı. Pandemi sırasında COVID-19 tanısı alanların daha yüksek oranda anksiyete semptomları sergiledikleri; pandemi sürecinde ruh sağlığı açısından profesyonel bir destek alma ihtiyacı olduğunu düşünenlerin ise daha yüksek oranda depresyon, anksiyete ve stres semptomları sergiledikleri saptandı. Sağlık çalışanı olmayanların ve pandemi sürecinde ruh sağlığı açısından profesyonel bir destek alma ihtiyacı olduğunu düşünenlerin daha yüksek oranda travma sonrası stress bozukluğu semptomları sergilediği görüldü.

Sonuç: COVID-19 pandemisinin gebe ruh sağlığı üzerine etkilerini saptamak, erken müdahale yöntemlerini harekete geçirebilmek ve kanıta dayalı uygulamalar gerçekleştirebilmek adına önemli olacaktır.

Anahtar Kelimeler: Gebe, COVID-19, ruh sağlığı

Corresponding (iletişim): Esma Akpinar Aslan, Department of Psychiatry, School of Medicine, Tokat Gaziosmanpasa University, Tokat, Turkey E-mail (E-posta): esmaakpinaraslan@gmail.com 


\section{INTRODUCTION}

Coronavirus disease 2019 (COVID-19) was first reported in Wuhan, China in December 2019 and was declared as a pandemic by the World Health Organization (WHO) on 11 March 2020. The first COVID-19 case in Turkey was reported on 11 March 2020. As a major public health problem, the COVID-19 pandemic not only poses a major threat to human life but also significantly affects community mental health. Psychosocial stress factors that may be encountered during pandemics include health threats to ourselves and our loved ones, major changes in daily life routines, separation from family and friends, loss of income, economic impacts domestically and worldwide, disruptions in health services, and implementation of quarantine and social isolation measures. ${ }^{[1]}$ During the pandemic, people face not only the risk of themselves becoming infected but also the burden of coping with the illness or death of their relatives. Fear of catching the disease, being worried about contracting the disease or family members contracting the disease, concerns regarding how the disease will progress, and uncertainty in the overall process are intense sources of anxiety and stress response is inevitable. Factors such as previous experiences, personality traits, gender, age, and medical history may be effective in the various mental reactions shown in such periods. There are many potential sources of stress with a potential effect on mental health in the context of the current COVID-19 pandemic. Along with these stressors; anxiety, depression, fear, psychological stress, post-traumatic stress symptoms, and sleep problems are observed during the COVID-19 pandemic. ${ }^{[2]}$ As the negative effects of COVID-19 pandemic, which is widespread and has various effects, on the mental health of the community are so evident, it is possible to mention groups that can be considered special in terms of mental health, such as those with previously known psychiatric illnesses, children, individuals over 65 years of age, health care professionals or refugees. Pregnant women can also be considered as one of these special groups. ${ }^{[3]}$

Although most women consider pregnancy to be the most enjoyable period of their life, some women may experience periods that may result in various mental disorders, even in the normal course of pregnancy. Mental disorders that may be encountered during pregnancy pose risks for the physical, cognitive and psychological development of infants as well as having risks in terms of the general health and functionality of the mother. Results of meta-analysis on the mental disorders that may be encountered during pregnancy have shown that the prevalence of depression in the perinatal period is $11.9 \%{ }^{[4]}$ whereas the prevalence of antenatal anxiety disorder is $15.2 \% .^{[5]}$ The results of a systematic review and meta-analysis evaluating the perinatal consequences of anxiety during pregnancy have shown that anxiety during pregnancy increases the risk of spontaneous preterm birth, low birth weight, small for gestational age, and small head circumference. ${ }^{[6]}$ Another meta-analysis has revealed that premature birth is associated with maternal depression. ${ }^{[7]}$
Pandemics that have affected the world, such as severe acute respiratory syndrome (SARS) and Middle East respiratory syndrome (MERS), has demonstrated that the mental health of pregnant women is more likely to be affected by such disease outbreaks. ${ }^{[8,9]}$ The weakening of social support systems with the restriction measures taken, financial difficulties, risk of infection, disruptions in daily routine, and frightening information about the epidemic negatively affect maternal mental health during pregnancy. These potential sources of maternal stress have been identified as risk factors for mental health problems during the COVID-19 pandemic. ${ }^{[10]}$ For these reasons, it can be said that pregnant women are in the higher risk group as their mental health is negatively affected during the COVID-19 pandemic. ${ }^{[11]}$ In a study conducted by Saccone et al. ${ }^{[12]}$ involving 100 pregnant women, the authors reported that the psychological effects of COVID-19 among pregnant women were moderate and two-thirds of the participants had higher anxiety levels than normal. According to the results of another cross-sectional study, the prevalences of anxiety and depression symptoms were found to be $34.4 \%$ and $39.2 \%$, respectively. ${ }^{[13]}$ Wu et al. ${ }^{[14]}$ evaluated the mental health status of pregnant women before and after the pandemic and found that the rates of depressive symptom, anxiety scores, and selfharm thoughts of pregnant women were higher in the postpandemic period compared to the pre-pandemic. The authors further reported that depressive symptoms increased among pregnant women as the number of COVID-19 cases, suspicious infection, and daily mortality rates increased. ${ }^{[14]}$ Besides the results supporting that the COVID-19 pandemic causes anxiety and depressive symptoms in pregnant women, the presence of post-traumatic stress disorder (PTSD) symptoms have been also evaluated. In a study involving 1,123 women who were pregnant or recently gave birth during the COVID-19 pandemic, $10.3 \%$ of the participants were observed to have PTSD symptoms. ${ }^{[15]}$ In another study comparing the women, who were pregnant during the COVID-19 pandemic, with those who were pregnant before the COVID-19 pandemic; the prevalence of anxiety, depression, dissociative, and PTSD symptoms were observed to be higher in women who were pregnant during the pandemic period. ${ }^{[16]}$ In addition to the effects of the pandemic process on mental health during pregnancy, the rates of depression and anxiety in the early postpartum period are reported to be also high among women who are pregnant during the outbreak. ${ }^{[17]}$

The negative consequences of COVID-19 pandemic on the mental health of pregnant women and the mental disorders it may trigger pose risks for the physical, cognitive and psychological development of infants as well as having risks in terms of the general health and functionality of the mother. Existing data on the effects of COVID-19 on the mental health of pregnant women are limited. This study aimed to investigate the effects of COVID-19 pandemic on the mental health of pregnant women and to evaluate the prevalence of psychiatric symptoms. 


\section{MATERIALS AND METHODS}

\section{Participants}

A total of 113 women who were over 18 years of age, agreed to answer the online questionnaire prepared for the study and were pregnant at the time of completing the online questionnaire, were literate to answer the questions, were not mentally retarded, and did not have a neurological disease affecting cognitive functions were included the study. One of these participants was excluded from the study due to providing incomplete data. Therefore, 112 pregnant women were taken into account for further analyses.

\section{Procedure}

The study was conducted as an online cross-sectional study and conducted between January 1 and February 1, 2021. The online questionnaire created by the researchers using Google Forms was sent to the participants via e-mail. The first part of the questionnaire consisted of questions about sociodemographic characteristics and COVID-19. It was followed by the Depression Anxiety Stress Scale-Short Form (DASS-21) and PTSD Checklist for Diagnostic and Statistical Manual of Mental Disorders-Fifth Edition (DSM-5) (PCL-5).

\section{Instruments of Assessment}

Depression Anxiety Stress Scale-21- Short Form (DASS21): This scale has been developed from DASS-42, the longer version. ${ }^{[18,19]}$ The short-form consists of three subscales, each containing seven questions. There are a total of 21 questions aiming to measure depression, anxiety, and stress levels. It is a four-point Likert-type scale ( $0=$ "never", $1=$ "sometimes and occasionally", $2="$ quite often", and $3=$ "always"). The Turkish version of the scale was used in this study. ${ }^{[2]}$

PTSD Checklist for Diagnostic and Statistical Manual of Mental Disorders-Fifth Edition (DSM-5) (PCL-5): It is a five-point Likert-type ( $0="$ Not at all", $1=$ "A little bit", 2="Moderately", 3="Quite a bit" and 4="Extremely") scale designed to measure PTSD symptoms and the severity of these symptoms according to DSM-5 diagnostic criteria. ${ }^{[21]}$ The 20-item scale has four subscales namely re-experiencing, avoidance, negative alterations, and hyper-arousal. The scale also provides a total score and cut-off score for evaluating the frequency of symptoms. In the Turkish population, the cut-off point of the scale was found to be 48 for community samples. The Turkish version of the scale was used in this study. ${ }^{[22]}$

\section{Statistical Analysis}

Statistical analysis was performed using Statistical Package for Social Sciences (SPSS) version 15.0 software. Descriptive statistical methods (such as mean, standard deviation, median, minimum, maximum, frequency, percentage) were used for the expression of data. Mann Whitney $U$ test was used for the comparison of two groups whereas the Kruskal-Wallis test and post-hoc Dunn test were used for the comparisons of more than two groups. Spearman's correlation coefficient was used for correlation analysis. Results were evaluated at a $95 \%$ confidence interval and a $\mathrm{p}$ value of $<0.05$ was considered statistically significant.

Ethics Statement: Approval for the study was granted by the Sakarya University Ethical Committee with Approval no:71522473/050.01.04/631, dated December 28, 2020. All patients signed informed consent for participation in this study, and their anonymity is preserved.

\section{RESULTS}

A total of 112 pregnant women with a mean age of $31.06( \pm 4.19)$ years were included in the study. The week of gestation ranged from five to 40 weeks, and the number of children ranged from zero to two. All participants were married and most of them $(81.3 \%)$ were living in a metropolitan area. Majority of the participants $(93.8 \%)$ were university graduates. Of pregnant women, $25.9 \%$ were health care professionals, $8.9 \%$ stated that they were working actively during the pandemic. This rate was $20.7 \%$ among health care professionals and $4.6 \%$ among those who were not health care professionals. Of the pregnant women, $3.6 \%$ stated that they were still smoking but they decreased their consumption during the pandemic. None of them were using alcohol or drugs. There was a systemic disease (thyroid disease being the most common)requiring follow-up during pregnancy in $13.4 \%$ of the pregnant women while $18.8 \%$ had previously applied to a psychiatry clinic and $7.1 \%$ had a diagnosed mental illness (anxiety being the most common). The proportion of participants diagnosed with COVID-19 during the pandemic was $11.6 \%(n=13)$, and only one of these patients received inpatient treatment. Of the participants, $69.6 \%$ had a relative diagnosed with COVID-19 during the pandemic and $46.4 \%$ knew someone who died due to COVID-19. The rate of pregnant women who thought they need professional support for mental health during the pandemic was $22.3 \%$ and the rate of those who felt anxious about the pregnancy process due to the COVID-19 pandemic was found to be $73.2 \%$ (Table 1).

Scores obtained from DASS-21 and PCL-5 scales are shown in Table 2. The DASS-21 subscale score for depression was 4.20 $( \pm 3.91)$ whereas it was $3.75( \pm 3.50)$ for the anxiety subscale and $5.68( \pm 3.81)$ for the stress subscale. Total PCL-5 score was $31.29( \pm 16.85)$.

The comparison of DASS-21 scale scores according to the sociodemographic characteristics of the participants revealed that there was no statistically significant difference in DASS- 21 subscale scores according to the week of gestation, number of children, occupation, working during the epidemic, presence of a systemic disease requiring follow-up during pregnancy, previous application to a psychiatry clinic, a diagnosed psychiatric illness, having a relative diagnosed with COVID-19, knowing someone who died due to COVID-19, and feeling anxious about pregnancy due to COVID-19 pandemic $(p>0.05)$. Participants who were living in districts and smaller settlements were observed to have statistically significantly higher DASS-21 anxiety and stress subscales scores compared 


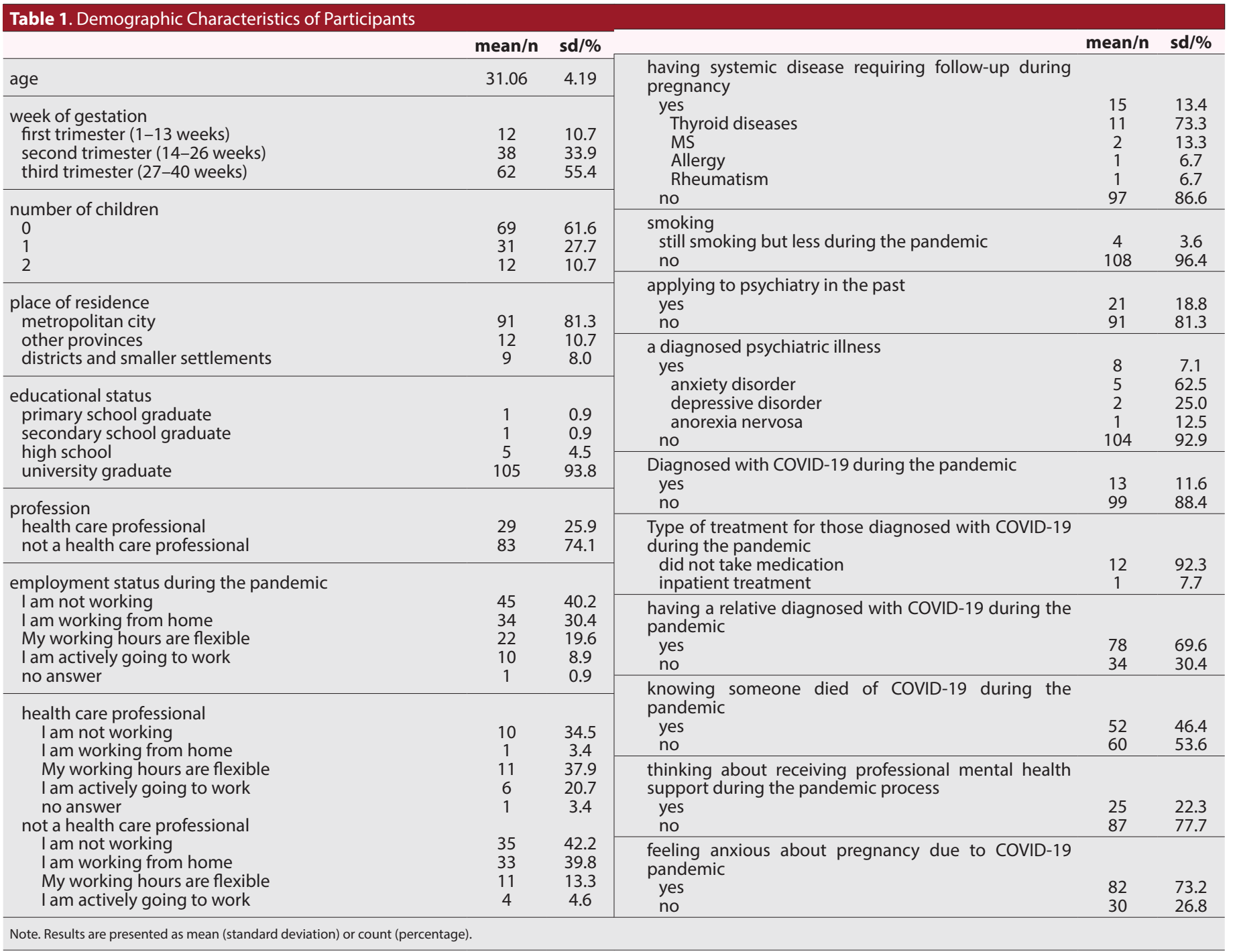

Table 2. DASS- 21 and PCL-5 scale scores of the participants

\begin{tabular}{lccccc} 
& Mean & SD & median & min & max \\
\hline Total DASS-21 score & & & & & \\
depression subscale score & 4.20 & 3.91 & 3 & 0 & 14 \\
anxiety subscale score & 3.75 & 3.50 & 3 & 0 & 14 \\
stress subscale score & 5.68 & 3.81 & 5.5 & 0 & 16 \\
\hline Total PCL-5 score & 31.29 & 16.85 & 28 & 1 & 67 \\
re-experiencing & 6.82 & 4.11 & 7 & 0 & 15 \\
avoidance & 3.31 & 2.07 & 3 & 0 & 8 \\
negative alterations & 11.73 & 6.34 & 11.5 & 0 & 25 \\
hyper-arousal & 9.42 & 5.54 & 8 & 0 & 23 \\
\hline
\end{tabular}

Note. DASS-21: Depression Anxiety Stress Scale-21, PCL-5: Posttraumatic Stress Disorder (PTSD) Checklist for Diagnostic and Statistical Manual of Mental Disorders, Fifth Edition

to those who were living in other settlements $(p=0.020$ and $p=0.028$, respectively). The anxiety subscale score was found to be statistically significantly higher in those who were diagnosed with COVID-19 during the pandemic than those who were not $(p=0.23)$. All DASS-21 subscale scores were significantly higher in those who thought they needed professional support for mental health during the pandemic than those who did not (Table 3).
The comparison of PCL-5 scale scores according to the sociodemographic characteristics of the participants revealed that there was no statistically significant difference in PCL-5 subscale scores according to the week of gestation, number of children, place of residence, working during the epidemic, presence of a systemic disease requiring follow-up during pregnancy, previous application to a psychiatry clinic, a diagnosed psychiatric illness, being diagnosed with COVID-19 during the pandemic, having a relative diagnosed with COVID-19, knowing someone who died due to COVID-19, and feeling anxious about pregnancy due to COVID-19 pandemic ( $p>0.05)$. The PCL-5 scale score was found to be statistically significantly higher in participants who were health care professionals than those who were not and in those who thought they needed professional support for mental health during the pandemic than those who did not $(p=0.041$ and $p=0.001$, respectively) (Table 4).

When the sociodemographic characteristics of the participants and PCL-5 subscale scores compared, no statistically significant 
difference was observed in PCL-5 subscale scores according to the week of gestation, number of children, place of residence, working during the epidemic, presence of a systemic disease requiring follow-up during pregnancy, previous application to a psychiatry clinic, a diagnosed psychiatric illness, knowing someone who died due to COVID-19, and feeling anxious about pregnancy due to COVID-19 pandemic ( $p>0.05$ ). Negative alterations subscale score was found to be statistically significantly higher among those who were not health care professionals than health care professionals $(p=0.047)$. The re-experiencing subscale score was statistically significantly higher in those who were diagnosed with COVID-19 during the pandemic compared to those who were not and in those who had a relative diagnosed with COVID-19 compared to those who do not ( $p=0.046$ and $p=0.042$, respectively). All PCL-5 subscale scores were significantly higher in those who thought they needed professional support for mental health during the pandemic than those who did not (Table 5).

Table 3. Comparison of DASS-21 subscale scores according to the characteristics of the participants

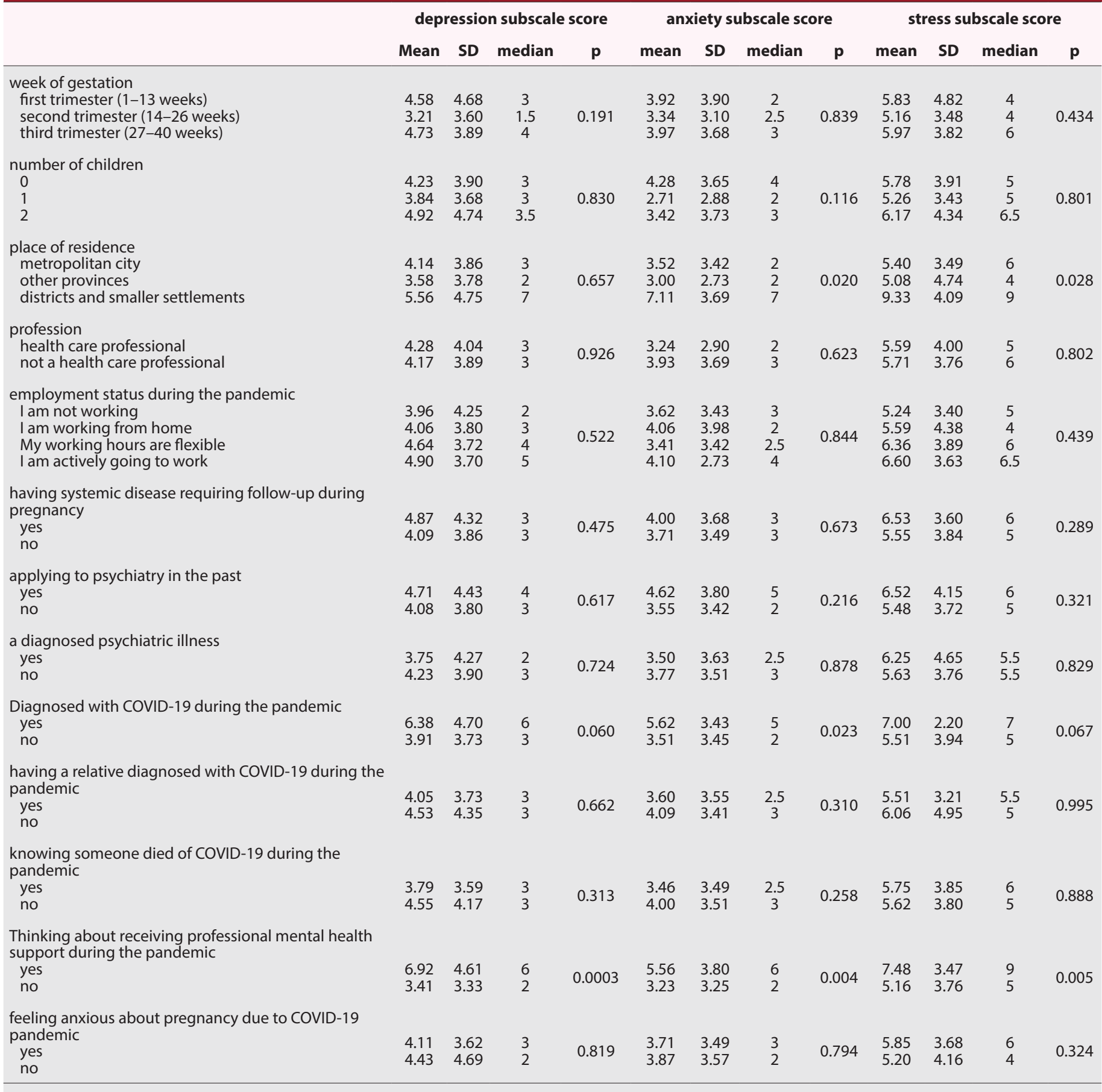

Note. DASS-21: Depression Anxiety Stress Scale-21 


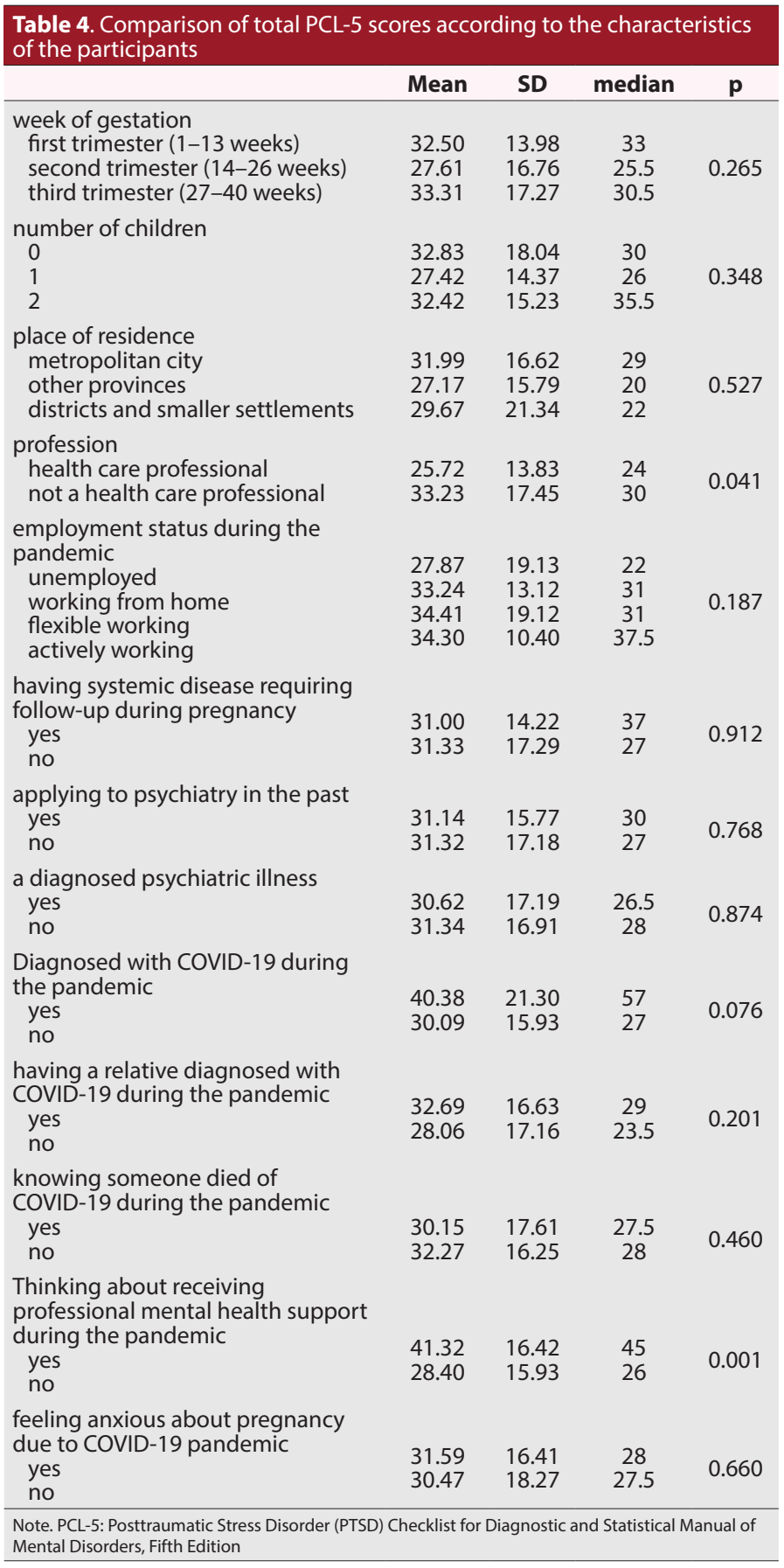

\section{DISCUSSION}

Effects of the pandemic on the mental health of pregnant women are as very important as the effects of COVID-19 on the physical health of pregnant women and babies. In the present study investigating the effects of the COVID-19 pandemic on the mental health of pregnant women, the DASS-21 depression subscale score was $4.20( \pm 3.91)$, the anxiety subscale score was $3.75( \pm 3.50)$, and the stress subscale score was $5.68( \pm 3.81)$, and the PCL-5 total score was $31.29( \pm 16.85)$. Anxiety and stress symptoms were higher among those who were living in districts and smaller settlements whereas those diagnosed with COVID-19 during the pandemic were observed to have higher anxiety symptoms and those who thought they needed professional support for mental health during the pandemic had higher depression, anxiety and stress symptoms. The prevalence of PTSD symptoms were found to be higher among participants who were not health care professionals and who thought they needed professional support for mental health during the pandemic. Women who were not health care professionals were observed to exhibit symptoms of PTSD listed under the negative alterations more while those who were diagnosed with COVID-19 during the pandemic and those who had a relative diagnosed with COVID-19 were observed to exhibit re-experiencing symptoms more. Those who thought they needed professional support for mental health during the pandemic process were found to have higher PTSD symptoms in all areas.

The evaluation of studies investigating the effects of pandemic on the mental health of pregnant women at the level of anxiety, depression, stress and PTSD symptoms shows that the results generally support that mental health is affected negatively; however, there are differences between the rates. In a study by Berhelot et al. ${ }^{[16]}$ involving two groups who were pregnant before the COVID-19 pandemic and who were pregnant during the pandemic period, those who were pregnant during the pandemic period showed more severe depression, anxiety, and PTSD symptoms. Results of a cross-sectional study involving a total of 819 participants (544 pregnant women and 315 non-pregnant women) revealed that the prevalence of depression, anxiety, physical discomfort, insomnia, and PTSD symptoms in the pregnant group were $5.3 \%, 6.8 \%, 2.4 \%, 2.6 \%$, and $0.9 \%$, respectively, while these rates were $17.5 \%, 2.5 \%, 5.4 \%$, and $5.7 \%$ in the non-pregnant group, respectively. Following the adjustment for other covariates, the authors observed that pregnancy was associated with a reduced risk of depression $(\mathrm{OR}=0.23 ; 95 \%$ $\mathrm{Cl}: 0.12-0.45)$, anxiety ( $\mathrm{OR}=0.26 ; 95 \% \mathrm{Cl}: 0.16-0.42)$, insomnia $(\mathrm{OR}=0.19 ; 95 \% \mathrm{Cl}: 0.06-0.58)$, and PTSD $(\mathrm{OR}=0.15 ; 95 \% \mathrm{Cl}$ : $0.04-0.53){ }^{[23]} \mathrm{A}$ meta-analysis including eight studies showed that the prevalence of anxiety symptoms was significantly increased during the COVID-19 pandemic compared to before and there was an increase in scale scores related to depressive complaints; however, it was suggested that this increase was not significant compared to the pre-pandemic period ${ }^{[8]}$ In the present study, $73.2 \%$ of the pregnant women stated that they felt anxious about the pregnancy process due to the COVID-19 pandemic and their scale scores showed that they exhibited subthreshold depression, anxiety, stress, and PTSD symptoms. These differences in results may be due to the fact that the evaluation scales used are different, and the studies are mostly cross-sectional and have been conducted at different stages of the epidemic.

In a study by Saccone et al. ${ }^{[12]}$ anxiety levels were higher and the psychological impact of the COVID-19 outbreak was more severe in women in the first trimester of pregnancy compared to those who were in the second or third trimester 
Table 5. Comparison of PCL-5 subscale scores according to the characteristics of the participants

\begin{tabular}{|c|c|c|c|c|c|c|c|c|c|c|c|c|c|c|c|c|}
\hline & \multicolumn{4}{|c|}{ re-experiencing score } & \multicolumn{4}{|c|}{ avoidance subscale score } & \multicolumn{4}{|c|}{$\begin{array}{l}\text { negative alterations subscale } \\
\text { score }\end{array}$} & \multicolumn{4}{|c|}{ hyper-arousal subscale score } \\
\hline & Mean & SD & median & $\mathbf{p}$ & mean & SD & median & $\mathbf{p}$ & mean & SD & median & $\mathbf{p}$ & mean & SD & median & $\mathbf{p}$ \\
\hline \multicolumn{17}{|l|}{ week of gestation } \\
\hline first trimester (1-13 weeks) & 7.58 & 4.36 & 9 & & 3.42 & 2.19 & 4 & & 12.17 & 6.10 & 10 & & 9.33 & 3.58 & 7 & \\
\hline second trimester (14-26 weeks) & 5.95 & 4.08 & 4.5 & 0.220 & 2.95 & 2.00 & 3 & 0.425 & 10.26 & 5.90 & 10 & 0.249 & 8.45 & 5.71 & 7.5 & 0.299 \\
\hline third trimester (27-40 weeks) & 7.21 & 4.07 & 7 & & 3.52 & 2.09 & 4 & & 12.55 & 6.57 & 13 & & 10.03 & 5.73 & 9 & \\
\hline \multicolumn{17}{|l|}{ number of children } \\
\hline 0 & 7.32 & 4.28 & 8 & & 3.58 & 2.19 & 4 & & 12.28 & 6.79 & 12 & & 9.65 & 5.81 & 8 & \\
\hline 1 & 5.87 & 3.82 & 5 & 0.268 & 2.74 & 1.90 & 2 & 0.200 & 10.26 & 5.46 & 10 & 0.331 & 8.55 & 5.01 & 7 & 0.581 \\
\hline 2 & 6.42 & 3.68 & 6 & & 3.25 & 1.60 & 4 & & 12.42 & 5.50 & 13 & & 10.33 & 5.47 & 10 & \\
\hline \multicolumn{17}{|l|}{$\begin{array}{l}\text { place of residence } \\
\text { metropolitan city }\end{array}$} \\
\hline other provinces & 7.04 & 4.13 & 7 & & 3.37 & 1.98 & 4 & & 11.91 & 6.34 & 12 & & 9.66 & 5.49 & 9 & \\
\hline districts and smaller & 5.58 & 3.87 & 4.5 & 0.490 & 3.17 & 2.25 & 2 & 0.697 & 10.00 & 4.86 & 8.5 & $0.56 /$ & 8.42 & 5.55 & 7 & 0.565 \\
\hline settlements & 6.22 & 4.38 & 4 & & 2.89 & 2.89 & 1 & & 12.22 & 8.23 & 10 & & 8.33 & 6.44 & 7 & \\
\hline \multicolumn{17}{|l|}{ profession } \\
\hline health care professional & 5.72 & 3.32 & 5 & 1110 & 2.79 & 1.76 & 2 & 2120 & 9.52 & 5.02 & 9 & & 7.69 & 5.20 & 7 & 0056 \\
\hline not a health care professional & 7.20 & 4.31 & 7 & 0.110 & 3.49 & 2.15 & 4 & 0.120 & 12.51 & 6.59 & 13 & 0.041 & 10.02 & 5.56 & 9 & 0.030 \\
\hline \multicolumn{17}{|l|}{$\begin{array}{l}\text { employment status during the } \\
\text { pandemic }\end{array}$} \\
\hline I am not working & 6.04 & 4.48 & 5 & & 2.82 & 2.28 & 2 & & 10.60 & 7.32 & 9 & & 8.40 & 5.88 & 7 & \\
\hline I am working from home & 7.41 & 3.63 & 8 & 0.346 & 3.65 & 1.65 & 4 & 0.193 & 12.26 & 5.46 & 12.5 & 0.312 & 9.91 & 4.33 & 10 & 0.404 \\
\hline My working hours are flexible & 7.55 & 4.44 & 7 & & 3.64 & 2.40 & 3 & & 12.68 & 6.33 & 13 & & 10.55 & 6.82 & 10 & \\
\hline I am actively going to work & 7.30 & 2.58 & 7.5 & & 3.90 & 1.10 & 4 & & 13.10 & 4.23 & 12.5 & & 10.00 & 4.78 & 9 & \\
\hline \multicolumn{17}{|l|}{$\begin{array}{l}\text { having systemic disease } \\
\text { requiring follow-up during }\end{array}$} \\
\hline $\begin{array}{l}\text { pregnancy } \\
\text { yes }\end{array}$ & 7.00 & 3.85 & 9 & 0.735 & 3.07 & 2.05 & 4 & 0.629 & 11.87 & 4.84 & 14 & 0.703 & 9.07 & 4.96 & 7 & 0.827 \\
\hline no & 6.79 & 4.17 & 6 & & 3.35 & 2.08 & 3 & & 11.71 & 6.56 & 10 & & 9.47 & 5.65 & 8 & \\
\hline \multicolumn{17}{|l|}{$\begin{array}{l}\text { applying to psychiatry in the } \\
\text { past }\end{array}$} \\
\hline yes & 7.05 & 3.58 & 8 & 0.759 & 3.38 & 1.75 & 4 & 0.786 & 11.71 & 6.25 & 10 & 0.829 & 9.00 & 5.05 & 9 & 0.931 \\
\hline no & 6.77 & 4.24 & 6 & & 3.30 & 2.15 & 3 & & 11.74 & 6.39 & 12 & & 9.52 & 5.67 & 8 & \\
\hline \multicolumn{17}{|l|}{ a diagnosed psychiatric illness } \\
\hline yes & 7.50 & 4.28 & 6 & & 3.50 & 2.00 & 3 & & 11.37 & 6.30 & 9.5 & & 8.25 & 5.15 & 8 & 0606 \\
\hline no & 6.77 & 4.12 & 7 & 0.026 & 3.30 & 2.08 & 3 & 0.154 & 11.76 & 6.37 & 12 & 0.199 & 9.51 & 5.58 & 8 & 0.000 \\
\hline \multicolumn{17}{|l|}{$\begin{array}{l}\text { Diagnosed with COVID-19 } \\
\text { during the pandemic }\end{array}$} \\
\hline yes & 9.15 & 5.16 & 13 & 0.046 & 4.08 & 2.50 & 6 & 0.113 & 15.23 & 8.21 & 22 & 0.075 & 11.92 & 5.91 & 16 & 0.087 \\
\hline no & 6.52 & 3.88 & 6 & & 3.21 & 2.00 & 3 & & 11.27 & 5.95 & 10 & & 9.09 & 5.44 & 8 & \\
\hline \multicolumn{17}{|l|}{$\begin{array}{l}\text { having a relative diagnosed } \\
\text { with COVID-19 during the }\end{array}$} \\
\hline $\begin{array}{l}\text { pandemic } \\
\text { yes }\end{array}$ & 7.33 & 4.07 & 7 & 0.042 & 3.44 & 2.04 & 4 & 0.299 & 11.97 & 6.22 & 11.5 & 0.657 & 9.95 & 5.53 & 9 & $0.14 \varepsilon$ \\
\hline no & 5.65 & 4.02 & 4 & & 3.03 & 2.14 & 3 & & 11.18 & 6.66 & 11 & & 8.21 & 5.45 & 7 & \\
\hline \multicolumn{17}{|l|}{$\begin{array}{l}\text { knowing someone died of } \\
\text { COVID-19 during the pandemic }\end{array}$} \\
\hline yes & 6.23 & 4.15 & 5 & 0.163 & 3.13 & 2.12 & 3 & 0378 & 11.13 & 6.49 & 10.5 & 0307 & 9.65 & 5.97 & 9 & \\
\hline no & 7.33 & 4.05 & 8 & & 3.47 & 2.03 & 4 & $0.3 / 8$ & 12.25 & 6.20 & 12.5 & $0.38 \%$ & 9.22 & 5.18 & 8 & 0.805 \\
\hline \multicolumn{17}{|l|}{$\begin{array}{l}\text { Thinking about receiving } \\
\text { professional mental health } \\
\text { support during the pandemic }\end{array}$} \\
\hline yes & 9.44 & 3.69 & 10 & 0.0003 & 4.44 & 2.00 & 5 & 0.002 & 15.56 & 6.08 & 16 & 0.001 & 11.88 & 5.67 & 13 & 0.015 \\
\hline no & 6.07 & 3.93 & 5 & & 2.99 & 1.99 & 3 & & 10.63 & 6.00 & 10 & & 8.71 & 5.33 & 8 & \\
\hline \multicolumn{17}{|l|}{$\begin{array}{l}\text { feeling anxious about } \\
\text { pregnancy due to COVID-19 } \\
\text { pandemic }\end{array}$} \\
\hline $\begin{array}{l}\text { pandemic } \\
\text { yes }\end{array}$ & 6.87 & 3.90 & 7 & 0.784 & 3.40 & 2.02 & 4 & 0.526 & 11.84 & 5.96 & 12 & 0.688 & 9.48 & 5.65 & 8 & 0.974 \\
\hline no & 6.70 & 4.72 & 5 & & 3.07 & 2.23 & 3 & & 11.43 & 7.37 & 10 & & 9.27 & 5.33 & 8.5 & \\
\hline
\end{tabular}

Note. PCL-5: Posttraumatic Stress Disorder (PTSD) Checklist for Diagnostic and Statistical Manual of Mental Disorders, Fifth Edition

of pregnancies. In the present study, there was no statistically significant difference in terms of DASS-21 and PLC-5 scale scores according to the week of gestation.

Interestingly, the results of the present study showed that the prevalence of PTSD symptoms was higher among those who were not health care professionals. In many studies conducted during the COVID-19 pandemic, in which health care professionals who were playing an active role in combating pandemic and at higher risk of being infected were included, this group were reported to have significantly higher depression, anxiety and PTSD symptoms compared to the normal population. ${ }^{[24-26]}$ The differences in the present results may be attributed to the fact that the occupational distribution of the study population is not homogeneous and that the group mostly consists of those who are not health care professionals. 
Furthermore, people infected with COVID-19 are exposed to many stressors and traumatic events, such as hospitalization, isolation, infection or death of their relatives, besides the symptoms of the disease. In a cross-sectional study involving patients who were hospitalized due to COVID-19 infection and discharged, the prevalence of moderate-to-severe anxiety, moderate-to-severe depression, and PTSD was found to be $10.4 \%, 19 \%$ and $12.4 \%$, respectively. ${ }^{[27]}$ Another study involving 714 individuals who were hospitalized due to COVID-19 infection reported the prevalence of significant PTSD symptoms associated with COVID-19 to be $96.2 \% .{ }^{[28]} \mathrm{In}$ another study involving 307 patients who were hospitalized due to COVID-19 infection, the authors reported that $18.6 \%$ of the participants exhibited depressive symptoms and $13.4 \%$ exhibited anxiety symptoms. ${ }^{[29]}$ Compatible with the literature, we found that anxiety symptoms were higher in those diagnosed with COVID-19 during the pandemic. Furthermore, participants who were diagnosed with COVID-19 during the pandemic and those who had a relative diagnosed with COVID-19 exhibited the symptoms of reexperiencing more.

Studies have shown that psychiatric symptoms worsen in patients with previously known mental disorders. ${ }^{[30,31]}$ Berthelot et al. ${ }^{[16]}$ reported that among women who were pregnant during the COVID-19 pandemic, those with a previous psychiatric diagnosis exhibited a higher rate of stress and psychiatric symptoms. In the present study, the rate of those with a previous psychiatric diagnosis was quite low $(7.1 \%)$. The comparison of the scale scores showed that there was no statistically significant difference between these participants and those without a known psychiatric disorder. However; depression, anxiety, stress, and PTSD symptoms were observed to be higher among women who thought they needed professional support for mental health during the pandemic. Given that these individuals may be more likely to receive a diagnosis when they apply to a psychiatry outpatient clinic, we can say that this is an expected finding.

This study has some limitations. First of all, it was designed as a cross-sectional study and therefore, a cause-effect analysis could not be performed among study variables. Other limitations include collecting data with an online questionnaire using self-report scales and not conducting a diagnostic clinical interview. On the other hand, the fact that it is one of the few studies investigating the effects of the COVID-19 pandemic on the mental health of pregnant women in Turkey is one of its strengths. Most of the studies on COVID-19 in pregnancy have focused on the physical effects of the pandemic on infected mothers and probability of transmission of the virus from mother to baby. Mental health problems of pregnant women are just as important as physical problems and should not be ignored.

\section{CONCLUSION}

This study has provided a cross-sectional overview of the effects of the COVID-19 pandemic on the mental health of pregnant women. In conclusion, pregnant women diagnosed with COVID-19 during the pandemic have been observed to exhibit a higher rate of anxiety symptoms and those who believe that they need professional support for mental health during the pandemic show higher rates of depression, anxiety, and stress symptoms. The prevalence of PTSD symptoms has been observed to be higher among participants who are not health care professionals and who believe they need professional support for mental health during the pandemic. The negative consequences of COVID-19 pandemic and the mental disorders it may trigger pose risks for the physical, cognitive and psychological development of infants as well as having risks in terms of the general health and functionality of the mother. Therefore, determining the effects of the COVID-19 pandemic on the mental health of pregnant women will be important to put early intervention methods in action and implement evidence-based practices.

\section{ETHICAL DECLARATIONS}

Ethics Committee Approval: Approval for the study was granted by the Sakarya University Ethical Committee with Approval no:71522473/050.01.04/631, dated December 28, 2020.

Informed Consent: Because the study was designed retrospectively, no written informed consent form was obtained from patients.

Referee Evaluation Process: Externally peer-reviewed.

Conflict of Interest Statement: The author(s) declared no potential conflicts of interest with respect to the research, authorship, and/or publication of this article.

Financial Disclosure: The authors declared that this study has received no financial support.

Author Contributions: All of the authors declare that they have all participated in the design, execution, and analysis of the paper, and that they have approved the final version.

\section{REFERENCES}

1. Taylor S. The Psychology of Pandemics: Preparing for the Next Global Outbreak of Infectious Disease. Newcastle upon Tyne: Cambridge Scholars Publishing; 2019.

2. Talevi D, Socci V, Carai M et al. Mental health outcomes of the CoViD-19 pandemic. Riv Psichiatr 2020;55(3):137-44.

3. Brooks SK, Webster RK, Smith LE et al. The psychological impact of quarantine and how to reduce it: rapid review of the evidence. The Lancet 2020;395(10227).

4. Woody CA, Ferrari AJ, Siskind DJ, Whiteford HA, Harris MG. A systematic review and meta-regression of the prevalence and incidence of perinatal depression J Affect Disord 2017;219:86-92.

5. Dennis CL, Falah-Hassani K, Shiri R. Prevalence of antenatal and postnatal anxiety: systematic review and meta-analysis. $\mathrm{Br} J$ Psychiatry 2017;210(5):315-23. 
6. Grigoriadis S, Graves L, Peer M et al. Maternal Anxiety During Pregnancy and the Association With Adverse Perinatal Outcomes: Systematic Review and Meta-Analysis. J Clin Psychiatry 2018;79(5):17r12011.

7. Grigoriadis $S$, VonderPorten $E H$, Mamisashvili $L$ et al. The impact of maternal depression during pregnancy on perinatal outcomes: a systematic review and meta-analysis. J Clin Psychiatry 2013;74(4):e32141.

8. Hessami K, Romanelli C, Chiurazzi M, Cozzolino M. COVID-19 pandemic and maternal mental health: a systematic review and meta-analysis. J Matern Fetal Neonatal Med 2020:1-8.

9. Schwartz DA, Graham AL. Potential Maternal and Infant Outcomes from (Wuhan) Coronavirus 2019-nCoV Infecting Pregnant Women: Lessons from SARS, MERS, and Other Human Coronavirus Infections. Viruses 2020;12(2):194

10. Caparros-Gonzalez RA, Alderdice F. The COVID-19 pandemic and perinatal mental health. J Reprod Infant Psychol 2020;38(3):223-5.

11. Thapa SB, Mainali A, Schwank SE, Acharya G. Maternal mental health in the time of the COVID-19 pandemic. Acta Obstet Gynecol Scand 2020;99(7):817-8

12. Saccone G, Florio A, Aiello F, et al. Psychological impact of coronavirus disease 2019 in pregnant women. Am J Obstet Gynecol 2020;223(2):2935.

13. Farrell T, Reagu S, Mohan S, et al. The impact of the COVID-19 pandemic on the perinatal mental health of women J Perinat Med. 2020;48(9):971-6.

14. Wu Y, Zhang C, Liu H et al. Perinatal depressive and anxiety symptoms of pregnant women during the coronavirus disease 2019 outbreak in China. Am J Obstet Gynecol 2020;223(2):240.e1-240.e9.

15. Liu CH, Erdei C, Mittal L. Risk factors for depression, anxiety, and PTSD symptoms in perinatal women during the COVID-19 Pandemic. Psychiatry Res 2021;295:113552.

16. Berthelot N, Lemieux R, Garon-Bissonnette J, Drouin-Maziade C, Martel É, Maziade M. Uptrend in distress and psychiatric symptomatology in pregnant women during the coronavirus disease 2019 pandemic. Acta Obstet Gynecol Scand 2020;99(7):848-55.

17. Zanardo V, Manghina V, Giliberti L, Vettore M, Severino L, Straface G. Psychological impact of COVID-19 quarantine measures in northeastern Italy on mothers in the immediate postpartum period. Int J Gynaecol Obstet 2020;150(2):184-8.

18. Lovibond SH, Lovibond PF. Manual for the Depression Anxiety Stress Scales, (2nd ed.). Sydney, Australia: Pychology Foundation of Australia; 1995.

19. Lovibond PF, Lovibond SH. The structure of negative emotional states: comparison of the Depression Anxiety Stress Scales (DASS) with the Beck Depression and Anxiety Inventories Behav Res Ther. 1995;33(3):335-43.

20. Sarıcam H. (2018). The psychometric properties of Turkish version of Depression Anxiety Stress Scale-21 (DASS-21) in health control and clinical samples JCBPR 2018;7(1):19-30.

21. Weathers FW, Litz BT, Keane TM, Palmieri PA, Marx BP, Schnurr PP. The PTSD Checklist for DSM-5 (PCL-5). 2013. Scale available from the National Center for PTSD at www.ptsd.va.gov.

22. Boysan M, Guzel Ozdemir P, Ozdemir O, Selvi Y, Yilmaz E, Kaya N. Psychometric properties of the Turkish version of the PTSD Checklist for Diagnostic and Statistical Manual of Mental Disorders, (PCL-5). Psychiatry and Clinical Psychopharmacology 2017;27(3): 300-10.

23. Zhou Y, Shi H, Liu Z et al. The prevalence of psychiatric symptoms of pregnant and non-pregnant women during the COVID-19 epidemic. Transl Psychiatry 2020;10(1):319.

24. Spoorthy MS, Pratapa SK, Mahant S. Mental health problems faced by healthcare workers due to the COVID-19 pandemic-A review. Asian J Psychiatr 2020;51:102119.

25. Bohlken J, Schömig F, Lemke MR, Pumberger M, Riedel-Heller SG. COVID19-Pandemie: Belastungen des medizinischen Personals [COVID-19 Pandemic: Stress Experience of Healthcare Workers - A Short Current Review]. Psychiatr Prax 2020;47(4):190-7.

26. Vizheh M, Qorbani M, Arzaghi SM, Muhidin S, Javanmard Z, Esmaeili M. The mental health of healthcare workers in the COVID-19 pandemic: $A$ systematic review. J Diabetes Metab Disord 2020;19(2):1-12.
27. Liu D, Baumeister RF, Veilleux JC et al. Risk factors associated with mental illness in hospital discharged patients infected with COVID-19 in Wuhan, China. Psychiatry Res 2020;292:113297.

28. Bo HX, Li W, Yang Y et al. Posttraumatic stress symptoms and attitude toward crisis mental health services among clinically stable patients with COVID-19 in China. Psychol Med 2020:1-2.

29. Dai LL, Wang X, Jiang TC et al. Anxiety and depressive symptoms among COVID-19 patients in Jianghan Fangcang Shelter Hospital in Wuhan, China. PLoS One 2020;15(8):e0238416.

30. Zhou J, Liu L, Xue P, Yang X, Tang X. Mental Health Response to the COVID-19 Outbreak in China. Am J Psychiatry 2020;177(7):574-5.

31. Fernández-Aranda F, Casas M, Claes L et al. COVID-19 and implications for eating disorders. Eur Eat Disord Rev 2020;28(3):239-45. 